\title{
SURGICAL TREATMENT OF ATRIAL FIBRILLATION IN ELDERLY PATIENTS UNDERGOING HIGH RISK CARDIAC SURGERY
}

\author{
Mohsin Uzzaman ${ }^{1}$, Imthiaz Manoly², Mohini Panikkar², Maciej Matuszewski², Nicolas \\ Nikolaidis $^{1}$, and John Billing ${ }^{2}$ \\ ${ }^{1}$ Affiliation not available \\ ${ }^{2}$ New Cross Hospital
}

May 27, 2021

\begin{abstract}
BACKGROUND/AIM To evaluate outcomes of concurrent Cox-Maze procedures in elderly patients undergoing high-risk cardiac surgery. MEHODS We retrospectively identified patients aged over 70 years with Atrial Fibrillation (AF) from 2011 to 2017 who had two or more other cardiac procedures. They were subdivided into two groups: 1. Cox-Maze IV AF ablation 2. No-Surgical AF treatment. Patients requiring redo procedures or those who had isolated PVI or LAAO were excluded. Heart rhythm assessed from Holter reports or 12-lead ECG. Follow-up data collected through telephone consultations and medical records. RESULTS There were 239 patients. Median follow up was 61 months. 70 patients had Cox-Maze IV procedures (29.3\%). Demographic, intra- and post-operative outcomes were similar between groups although duration of pre-operative AF was shorter in Cox-Maze group ( $\mathrm{p}=0.001)$. One (1.4\%) patient in Cox maze group with 30-day mortality compared to 14 (8.2\%) the control group $(\mathrm{p}=0.05)$. Sinus rhythm at annual and latest follow-up was $84.9 \%$ and $80.0 \%$ respectively in Maze group significantly better than No-Surgical AF treatment groups $(\mathrm{P}<0.001)$. 160 patients $(66.9 \%)$ were alive at long-term follow-up with better survival curves in Cox Maze group compared to No-Surgical treatment group $(\mathrm{p}=0.02)$. There was significantly higher proportion of patients in NYHA 1 status in Cox-Maze group ( $\mathrm{p}=0.009)$. No differences observed in freedom from stroke $(\mathrm{p}=0.80)$ or permanent pacemaker $(\mathrm{p}=0.33)$. CONCLUSIONS. Surgical ablation is beneficial in elderly patients undergoing high-risk surgery - promoting excellent long-term freedom from AF and symptomatic/prognostic benefits. Therefore, surgical risk need not be reason to deny benefits of concomitant AF-ablation.
\end{abstract}

\section{TITLE PAGE}

SURGICAL TREATMENT OF ATRIAL FIBRILLATION IN ELDERLY PATIENTS UNDERGOING HIGH RISK CARDIAC SURGERY

Short Running title: High Risk Ablation Surgery

Authors

1. Mohammed M Uzzaman ${ }^{1}$ - MRCS, MSc, BSc

2. Imthiaz Manoly ${ }^{1}$ - FRCS, MD

3. Mohini Pannikkar ${ }^{1}-\mathrm{MBChB}$

4. Maciej Matuszewski ${ }^{1}$ - FRCS, MD

5. Nicolas Nikolaidis ${ }^{1}-$ FRCS, MD

6. Stephen Billing ${ }^{1}$ - DPhil, FRCS

Institution 
${ }^{1}$ Department Of Cardiothoracic Surgery, New Cross Hospital, Wolverhampton, UK .

Corresponding author

Mohammed Mohsin Uzzaman

Apartment 211, St Martin's Gate, 5 Worcester Street, Birmingham B24BB

E-mail: mohsinuzzaman@yahoo.co.uk

Telephone: $+\mathbf{4 4}(0) \mathbf{7 9 6 2 2 3 4 3 9 3}$

Meeting Presentation:

Oral Presentation at European Association Of Cardiothoracic Surgery (EACTS). Virtual Meeting. Oct 8-10. 2020.

AATS Surgical Treatment For Arrhythmias and rhythm disorders. A Virtual Learning Experience. Virtual Poster. (Oct 30-31 2020).

WORD COUNT: 4495 words

Ethics and Integrity Policies

1. Data availability - Nil required

2. Funding statement - Self-funded

3. Conflicts of Interest - Mr Billing is consultant for AtriCure Inc

4. Institutional Review Board or waiver - Not required due to retrospective study

5. Patient consent statement - Not required

6. Permission to produce material from other sources - Not required

7. Clinical trial registration - Not required

ORCID ID: https://orcid.org/0000-0002-7918-1136

\section{ABSTRACT}

\section{BACKGROUND AND AIM OF STUDY}

To evaluate outcomes of concurrent Cox-Maze procedures in elderly patients undergoing high-risk cardiac surgery.

\section{MEHODS}

We retrospectively identified patients aged over 70 years with Atrial Fibrillation (AF) from 2011 to 2017 who had two or more other cardiac procedures. They were subdivided into two groups:

1. Cox-Maze IV AF ablation

2. No-Surgical AF treatment.

Patients requiring redo procedures or those who had isolated PVI or LAAO were excluded. Heart rhythm was assessed from Holter reports or 12-lead ECG. Follow-up data collected through telephone consultations and medical records.

\section{RESULTS}

There were 239 patients. Median follow up was 61 months. 70 patients had Cox-Maze IV procedures (29.3\%). Demographic, intra- and post-operative outcomes were similar between the groups although duration of preoperative AF was shorter in Cox-Maze group $(\mathrm{p}=0.001)$. One (1.4\%) patient in Cox maze group with 30-day mortality compared to $14(8.2 \%)$ the control group $(\mathrm{p}=0.05)$. Sinus rhythm at annual and latest follow-up was $84.9 \%$ and $80.0 \%$ respectively in Maze group - significantly better than No-Surgical AF treatment groups $(\mathrm{P}<0.001) .160$ patients $(66.9 \%)$ were alive at long-term follow-up with better survival curves in Cox Maze 
group compared to No-Surgical treatment group $(\mathrm{p}=0.02)$. There were a significantly higher proportion of patients in NYHA 1 status in Cox-Maze group $(\mathrm{p}=0.009)$. No differences observed in freedom from stroke $(\mathrm{p}=0.80)$ or permanent pacemaker $(\mathrm{p}=0.33)$.

\section{CONCLUSIONS.}

Surgical ablation is beneficial in elderly patients undergoing high-risk surgery - promoting excellent longterm freedom from AF and symptomatic/prognostic benefits. Therefore, surgical risk need not be a reason to deny benefits of concomitant AF-ablation.

\section{KEYWORDS}

1. Atrial Fibrillation

2. Cox-Maze IV

3. Ablation

4. Elderly

5. Outcomes

6. Long-term

\section{Introduction}

Atrial fibrillation (AF) is the most common cardiac arrhythmia, with a prevalence of $2.1 \%$ in people aged more than 65 years, with the highest prevalence in people aged more than 80 years [1]. The prevalence of AF is expected to double by 2050 [2]. The occurrence of AF is associated with age, sex, and, most importantly, cardiac disease. Fifty percent of patients undergoing mitral valve surgery present with AF [3], as do $1 \%$ to $6 \%$ of patients undergoing coronary artery bypass grafting or aortic valve surgery [4].

Several large studies, including the Framingham study, have shown that AF is associated with an increased risk for mortality and morbidity $[5,6]$. In the past decade, studies have suggested that patients who present for cardiac surgery with a significant history of AF have reduced survival over time if AF is left untreated $[4,7]$. Other studies have also found that patients who present with AF have worse perioperative outcomes, including a higher incidence of thomboembolic events like stroke and congestive heart failure [8-10].

The Cox maze procedure was originally designed in 1987 as a concomitant procedure for the treatment of AF in patients undergoing MVS [11]. After several iterations, the Cox-Maze IV procedure was introduced in 2002 [12]. The Cox Maze IV simplified the original procedure by replacing most of the "cut and sew" atrial incisions of the lesion set with linear lines of ablation, making the operation technically easier and faster to perform. Despite the proven success of the Cox-Maze procedure, referring physicians and cardiac surgeons remain somewhat reluctant to adopt the procedure for surgical ablation of AF. Gammie and colleagues published a study based on the Society of Thoracic Surgeons' database, which demonstrated that only $38 \%$ of patients presenting for cardiac surgery while experiencing AF underwent any type of corrective surgical ablation concomitantly with a valve or coronary bypass surgery [13]. The surgical complexity and predicted operative risk are major variables in the decision of whether to perform surgical ablation for AF at the time of other cardiac procedures, because there is a general perception that surgical ablation significantly increases the complexity, operating times and therefore risks for perioperative complications. Currently, no risk models are available for concomitant arrhythmia surgery; thus, the extent of the additional associated risk has been poorly defined. In addition the level of training required to perform surgical ablation and a lack of recognition of the clinical importance of AF may also contribute to the relatively low uptake of the procedure in clinical practice.

The treatment of elderly patients with AF remains a challenge due to concurrent morbidities and agerelated physiological changes. Anticoagulation therapies recommended to prevent the thromboembolic events associated with $\mathrm{AF}$ also have a greater risk of major bleeding complications in elderly patients. The number of elderly patients is increasing and this is reflected in surgical practice with more patients undergoing cardiac surgery in the last 15 years [14]. Very few studies have examined the efficacy of surgical AF ablation in elderly patients. As a result, the purpose of this study was to evaluate the outcomes of concurrent Cox 
maze procedures in elderly patients (aged[?] 70 years) who undergo high risk cardiac surgery (i.e. more than 2 additional concomitant procedures). We hypothesized that a concurrent Cox maze procedure does not worsen outcomes in elderly patients undergoing high-risk cardiac surgery.

\section{MATERIAL AND METHODS}

This was a single-center cohort study in which all data were collected prospectively for surgery occurring between January 2011 and December 2017. Patients with pre-operative AF, who were above 70 years and underwent 2 cardiac procedures with or without additional AF procedures were included in the study. Patients were divided into two groups based on how the AF was addressed: (1) Cox-maze IV procedure (2) Nil surgical AF treatment group. Patients undergoing redo procedures or who had isolated Pulmonary vein isolation (PVI) or left atrial appendage occlusion (LAAO) to address their AF were excluded from the study. History of preoperative atrial fibrillation was determined through our local database and type of atrial fibrillation was determined according to Heart Rhythm Society guidelines. The database was also used to gain additional preoperative characteristics and perioperative outcomes. Detailed follow-up data was collected for patients through telephone consultations and medical record review. In addition, reports from primary care physicians and cardiologists from referring centres were obtained if required. Rhythm status for patients who underwent a surgical ablation procedure was determined according to the Heart Rhythm Society guidelines and verified by electrocardiogram and Holter monitor. The Heart Rhythm Society definition of success (ie, all documented atrial Arrhythmias $>30$ seconds are considered a failure) was used to determine the return to sinus rhythm rate at first follow (usually 6 weeks), annual follow and long-term follow-up [15]. Anticoagulation status was also collected at the follow-up time points. Operative mortality was defined as death occurring within 30 days of operation or at any time point during the index hospitalization.

Operative Approach

Multiple surgeons performed the complete Cox-maze IV lesion set in a standard fashion as described previously. This consisted of a bilateral PVI, roof and connecting lesions between the right and left pulmonary veins, lesion to the left atrial appendage, mitral isthmus lesion, right intercaval lesion, right appendage lesion, right free wall lesion to the tricuspid annulus lesion and the coronary sinus lesion. The energy source used was cryothermia and bipolar radiofrequency (Medtronic, Minneapolis, Minn; AtriCure Inc, West Chester, Ohio). The left atrial appendage was occluded in all patients who had Cox-Maze IV. This was performed using the Atriclip device (AtriCure Inc, West Chester, Ohio). The patients in the "Nil procedure" group only had two cardiac procedures and served as our primary control group. The decision of whether to add the Cox Maze procedure to a specific surgical procedure was left to the discretion of the surgeon.

Statistical Analysis

Continuous data are presented as mean +/- standard deviation or Median +/- Interquartile range. Categorical data is presented as frequency (+/-percent) unless otherwise noted. Patient groups were compared usingc 2 or Fisher exact test for preoperative and postoperative categorical variables and student independent samples $\mathrm{t}$ test or Mann-Whitney $\mathrm{U}$ test for continuous measures as appropriate based on parametric test assumptions. Statistical significance was considered $\mathrm{p}<0.05,2$-tailed. Kaplan-Meier analysis was used to compare the groups on cumulative survival, freedom from AF, NYHA 1 status, freedom from permanent pacemaker insertion and freedom from stroke. Gehan-Behan-Wilcoxon test was used to assess significance of these survival analyses. All analyses were conducted using SPSS version 17.0 (SPSS Inc, Chicago, Ill) or GraphPad Prism, Version 6.00 for Mac (GraphPad Software, La Jolla, CA, USA).

\section{RESULTS}

\section{Patient details}

Between Jan 2011 and Dec 2017, there were 239 patients who were aged over 70 years with pre-operative AF who underwent two cardiac procedures (with or without any additional AF procedures). These were divided into the following groups depending on whether they had procedures to address their AF (Figure 1). After 
exclusion of patients described above, 70 patients (29.2\%) had Cox-Maze IV and 169 patients (70.8\%) had No Surgical-AF treatment (Figure 1).

The mean age of the whole cohort was $76.6+/-4.1$ years. The demographic data of the four groups are summarized in table 1. The logistic Euroscore was slightly lower in the Cox Maze group $(10.0+/-8.6)$ compared to the No Surgical AF treatment $(13.0+/-8.9)(\mathrm{p}=0.04)$. There were no differences in the NYHA 1 status $(\mathrm{p}=0.10)$ or NYHA 4 status $(\mathrm{p}=0.74)$ between the groups. There were a higher number of patients with pulmonary hypertension in the No Surgical AF treatment group (15.4\%) compared to the AF ablation group $(\mathrm{p}=0.02)$. Echocardiogram findings were comparable between the groups with respects to left atrial size $(p=0.48)$ and left ventricular function $(p=0.11)$. There was a significantly shorter duration of AF in the Cox-Maze group (19.9+/-22.3 months) compared to the No Surgical AF treatment group (94.2+/-113.7 months) $(\mathrm{p}=0.001)$. There were a significantly higher proportion of patients with PAF in the Cox-Maze group $(22.9 \%)$ compared to No Surgical AF treatment groups $(\mathrm{p}=0.00001)$.

\section{Intra-operative factors}

The specific intra-operative factors are summarized in table 2. 194 patients (81.1\%) were performed in an elective setting, with no difference between the groups $(\mathrm{p}=0.48)$. Unsurprisingly, the majority of patients in the cohort had MVS (186 patients, $77.8 \%)$ with no significant difference between the groups $(\mathrm{p}=0.17)$. There were 105 patients $(43.9 \%)$ who had concomitant CABG with a lower number in the Cox-Maze group $(27.1 \%$, $\mathrm{p}=0.003)$. The CPB times in the Cox-Maze group was 165.7+/-64.9 minutes which was comparable to the No Surgical AF treatment group $(\mathrm{p}=0.77)$. Similarly, the X-clamp times for the Cox-Maze group (135.1+/40.6 minutes) was not any higher $(\mathrm{p}=0.91) .9$ patients required IABP at the end of the case $(3.8 \%)$ with no difference between the groups $(\mathrm{p}=0.67)$.

\section{Perioperative outcomes}

The perioperative outcomes are summarized in table 3 . The overall 30-day mortality was $6.3 \%$ (15 patients) with no difference observed between the groups $(p=0.05)$. There was one peri-operative death (1.70\%) observed in the Cox-Maze Group compared to 14 patients (8.2\%) in the No-surgical AF treatment group. There were 3 cases of stroke in the entire cohort (1.2\%) which were observed in the No Surgical AF treatment group $(p=0.21)$. No patients in the Cox-Maze group suffered a peri-operative stroke. There was no difference in return to theatre $(\mathrm{p}=0.42)$ between the groups. There were 46 patients $(19.2 \%)$ who developed respiratory complications with no significant difference between the groups $(\mathrm{p}=0.06)$. $32(13.4 \%)$ patients developed AKI requiring temporary filtration/dialysis with no difference between the groups $(\mathrm{p}=0.16)$. There were 7 patients $(2.9 \%)$ with significant GI complications $(\mathrm{p}=0.50)$. There were 10 patients $(4.2 \%)$ who required in hospital-PPM with 3 cases $(4.3 \%)$ in the Cox-Maze group $(\mathrm{p}=0.96)$. The duration of ITU stay $(\mathrm{p}=0.25)$ and overall hospital stay $(\mathrm{p}=0.30)$ was comparable between the groups.

\section{Long-term outcomes}

The median follow-up was $58.9+/-26.4$ months. Freedom from AF is shown in Figure 2. At 12 months $84.9 \%$ of the Cox Maze group were in SR. These benefits persisted until latest follow-up (80\%) and were significantly superior to the No surgical AF treatment group $(\mathrm{P}<0.00001)$.

There were 79 mortalities (33.1\%) during the follow-up period. There was a clear survival advantage of the Cox-Maze group ( $\mathrm{p}=0.02)$ over the No Surgical AF treatment group (figure 4). It should be mentioned that all patients were over 70 years of age at the time of surgery.

There were 74 patients (31.0\%) who remained in NYHA 1 on long-term follow-up. There were clear functional benefits in the Cox-Maze ( $\mathrm{p}=0.009)$ compared to No Surgical AF treatment groups (figure 5). On follow-up echocardiography, the LVF was improved marginally in the Cox-Maze group compared to the pre-operative LVF $(1.0+/-2.2 \%)$. Conversely, the LVF worsened slightly in the control groups. Overall, the post-operative LVF was not significantly higher in the Cox-Maze group (55.2+/-8.3\%) compared to the No Surgical AF treatment group $(51.1+/-9.6 \%)$. 
There were 11 cases of stroke in the overall cohort on long-term follow-up (4.6\%). There were 2 patients in the Cox-Maze group (2.9\%) compared to 9 patients in the No Surgical AF treatment group (5.3\%). There were no significant differences $(\mathrm{p}=0.80)$ in the long-term freedom from stroke between the groups.

There were 19 patients who required PPM at long-term follow-up (7.9\%). 5 patients in the Cox-Maze group (7.1\%) compared to 14 in the No Surgical AF treatment group (8.3\%). There were no significant differences $(\mathrm{p}=0.33)$ in long-term freedom from PPM between the groups. Only 15 patients in the entire cohort $(6.3 \%)$ stopped taking oral anticoagulation at long-term follow-up with no comparable difference between the groups $(\mathrm{p}=0.06)$.

\section{DISCUSSION}

A substantial increase in arrhythmia surgery has occurred in recent years owing to both the increase in $\mathrm{AF}$ frequency in our ageing population and the introduction of ablative technologies that have made AF correction procedures easier to perform. The Cox-Maze IV remains the most effective surgical treatment for $\mathrm{AF}$ and is the only surgical procedure to receive an indication from the Food and Drug Administration for the treatment of AF $[16,17]$. Since its introduction in 2002, the Cox-Maze IV has shown excellent success rates with low morbidity and mortality rates. However, the efficacy of the Cox-Maze IV at late follow-up in elderly patients has remained poorly defined. This study evaluated the efficacy and safety of the Cox-Maze IV in high risk cardiac surgery in those patients aged above 70 years.

This study showed that surgical ablation was highly effective in the treatment of AF with $84.9 \%$ at annual follow-up and $80.0 \%$ at long-term follow-up. As expected, these results were far superior to the No-surgical AF treatment procedure groups. Our results confirm previous studies assessing long-term outcomes in elderly patients. Macgregor et al showed the freedom from atrial tachyarrhythmia on or off anti-arrhythmic drugs was $80 \%$ and $61 \%$ at 1 and 5 year follow-up respectively in elderly cohort aged $>75$ years who had had Cox Maze IV [17]. In another study, Ad and Colleagues showed freedom from atrial tachyarrhythmia after Cox-Maze IV in patients > 75 years was $90 \%, 85 \%$ and $60 \%$ at 6 months, 1 and 2 years respectively [18]. Our results were also favorable compared to catheter ablation studies in elderly patients. Bunch et al showed that 46 patients aged $>80$ years reported freedom from AF on or off anti-arrythmic drugs of $75 \%$ and under $30 \%$ at 1 and 5 year follow-up after catheter ablation [19].

It is clear that surgical ablation is under-utilized in current practice. One of the reasons is the perception that a concomitant procedure will increase the complexity and operating times of the procedure and thereby lead to higher peri-operative complications. This concern is likely to be accentuated in the elderly patients undergoing high risk surgery with multiple cardiac procedures. Our study clearly demonstrates that surgical ablation can be performed safely with low peri-operative complications in elderly patients undergoing 2 or more procedures. Operating times as reflected in CPB and X-Clamp times were not significantly increased by concomitant surgical ablation. No patient who had Cox-Maze IV or PVI had a post-operative stroke which is an important finding given the known morbidity and mortality associated with this complication.

Additionally, elderly patients in our study did not experience an increase in renal failure requiring dialysis, reoperation for bleeding, respiratory complications or longer ICU/hospital stay. These findings are similar to those previously published by Ad et al [18], as well as complication rates documented in other studies examining catheter-based ablation of AF in elderly patients [19]. On the basis of their findings, Ad et al, advocated that age should not be the only discriminatory factor in deciding whether to perform a concurrent Cox Maze procedure [18].

There were 3 patients requiring a PPM post-operatively after Cox Maze procedure (4.3\%) which is comparable to the other groups in our study. These rates are acceptable as elderly patients experience a greater rate of post-operative PPM compared with younger patients as demonstrated by a recent study by Macgregor et al [17]. Electrophysiological changes in atrial tissue due to increasing age may impair sinus node function and increase the risk of failed sinus node recovery. Despite this, our long-term need for PPM in the entire cohort was relatively low $(7.9 \%)$ and as a result, we were unable to capture any significant difference between the groups during long-term follow-up. 
The rate of death within the normal population for patients $>70$ years old carries significance when trying to interpret survival over time. Despite this, our study showed survival advantages of the Cox-Maze IV compared to the group that had no intervention. Of course, the patients receiving surgical ablation were selected and the survival difference may merely reflect the preoperative condition. Nonetheless, the sustained maintenance of SR following ablation may confer survival benefits in the Cox-Maze group. This is clearly demonstrated in previous studies that have shown patients who have surgery without concomitant AF ablation have poorer short and long-term outcomes than patients that come to surgery and are in SR [20,21]. In addition, AF was found to be an independent significant predictor of long-term mortality [22]. Ngaage et al demonstrated that pre-operative AF on patients undergoing cardiac surgery was associated with increased morbidity and decreased survival if not corrected [23-25]. Despite the inherent selection bias, our study adds to the evidence that even elderly patients undergoing high risk surgery will achieve mortality benefits with concomitant Cox-Maze IV procedures.

The performance of the Cox Maze procedure, the high rate and maintanence of SR and exclusion of the left atrial appendage may have an important effect on risk reduction of thromboembolic and bleeding events. Although the Kaplan-Meyer curve does not show a significantly lower rate of stroke in the Cox Maze group, the number of patients in the study was relatively small and most of our patients in all groups continued to remain on long-term anticoagulation. There are recent evidence suggesting that anticoagulation can be safely minimized 3-6 months after successful Cox-Maze procedure without increasing the risk of stroke or associated mortality [26], and this would be another advantage of successful ablation.

We are pleased with the finding that suggests reduced symptoms following the Cox-Maze procedure. This is demonstrated by a significantly higher number of patients who were in NYHA 1 status in the Cox-Maze group compared to the other group. The assessment of symptoms and quality of life is challenging, especially in this subgroup of elderly patients who underwent a concomitant surgical procedure due to valvular or coronary disease. As a result, part of their symptom benefits can be related to the functional improvement as a result of their main cardiac procedure. However, several studies have shown that the return and maintenance of SR for patients with pre-operative AF conveyed a significant increase in quality of life $[18,27,28]$. Ad et al also demonstrated improved quality of life through SF-12 and AF-specific questionnaire in the elderly cohort $>75$ years who had concomitant Cox-Maze IV [18]. Gu et al showed patients who were restored to SR postoperatively had significantly better NYHA status compared to those in AF [29]. They also demonstrated significantly improved LVF and decreased size of LA and RA [29]. Our study did not show that the LVF was significantly improved in the Cox-Maze group but it decreased in the other group. However, we feel the reverse remodelling effect and prevention of heart failure could contribute to the improvement in symptoms in these patients in SR.

\section{LIMITATIONS}

This study is a retrospective and non-randomized study. This means there is interval censoring as well as selection bias of the Cox-Maze group leading to better symptomatic and prognostic benefits in this selected group. Another potential limitation is that the cause of death was not available for all patients. Knowing if the cause of death was cardiac in origin would be of interest as many of these elderly patients carry several cormorbid diagnoses as highlighted by the very high Euroscore in the study cohort. Finally, incomplete follow-up for some of the patients may lead to the study suffering attrition and cause reporting biases.

\section{CONCLUSION}

The outcome of this study suggests that the concomitant Cox Maze procedure in patients $>70$ years undergoing multiple cardiac procedures is an excellent procedure for sinus rhythm conversion without increased surgical risks. Our study also demonstrates a significant symptomatic and prognostic benefit of surgical ablation in elderly patients. Ultimately, we feel that age and complexity of surgery should not be contraindications to performing the Cox-Maze procedure.

\section{Acknowledgment}


Nil

\section{Author contributions}

Mohammed Mohsin Uzzaman: Conceptualization; Data curation; Investigation; Visualization; Writingoriginal draft. Imthiaz Manoly: Data curation; Investigation; Visualization; Writing - original draft. Mohini Pannikkar: Conceptualization; Data curation; Investigation. Maciej Matuszewski: Data curation; Investigation; Writing - review \& editing. Nikolas Nikolaidis: Data curation; Investigation; Writing - review \& editing. Steve Billing: Conceptualization; Formal analysis; Investigation; Methodology, Writing - original draft. Writing - review \& editing.

\section{Figure Legends}

Figure 1. Breakdown of cases

Figure 2. Freedom from AF between the two group

Figure 3. Survival curve between the two group

Figure 4. NYHA 1 status between two group

\section{TABLES}

\begin{tabular}{llll}
\hline & COX MAZE $(\mathrm{n}=70)$ & NIL(n=169) & p-value \\
\hline AGE & $76.1+/-3.7$ & $77.2+/-4.3$ & 0.26 \\
GENDER & M 33 F 37 & M 89 F 80 & 0.78 \\
DIABETES & 8 & 39 & 0.13 \\
COPD & 14 & 27 & 0.74 \\
BMI & $26.4+/-5.0$ & $27.8+/-4.7$ & 0.22 \\
CR Cl & $59.3+/-20.0$ & $61.6+/-21.2$ & 0.51 \\
Recent MI & 4 & 6 & 0.11 \\
Smoking History & 23 & 85 & 0.48 \\
HTN & 41 & 106 & 0.31 \\
Previous CVA/TIA & 7 & 23 & 0.79 \\
NYHA 1 & 2 & 7 & 0.10 \\
NYHA IV & 18 & 47 & 0.74 \\
Pulmonary HTN & 3 & 26 & $\mathbf{0 . 0 2}$ \\
LVF & $54.8+/-5.8$ & $52.3+/-8.4$ & 0.11 \\
LA Size & $4.8+/-1.4$ & $5.1+/-1.1$ & 0.48 \\
AF Duration & $19.9+/-22.3$ & $94.2+/-113.7$ & $\mathbf{0 . 0 0 1}$ \\
PAF (\%) & $16(22.9)$ & $12(7.1 \%)$ & $\mathbf{0 . 0 0 0 0 1}$ \\
\hline
\end{tabular}

Table 1. Demographic data for the two study groups

Table 2. Intra-operative parameters in the two groups

\begin{tabular}{llll}
\hline & COX MAZE $(\mathrm{n}=70)$ & $\mathrm{NIL}(\mathrm{n}=169)$ & P-VALUE \\
\hline ELECTIVE & 60 & 134 & 0.48 \\
X-Clamp (min) & $135.1+/-40.6$ & $130.7+/-86.3$ & 0.91 \\
CPB (min) & $165.7+/-64.9$ & $160.4+/-58.9$ & 0.77 \\
CABG & 19 & 86 & $\mathbf{0 . 0 0 1}$ \\
Mitral Surgery & 51 & 135 & 0.23 \\
IABP Intra-op & 2 & 7 & 0.67 \\
\hline
\end{tabular}


Table 3. Peri-operative outcomes between the two groups

\begin{tabular}{llll}
\hline & COX MAZE $(\mathrm{n}=70)$ & NIL $(\mathrm{n}=169)$ & P-VALUE \\
\hline HOSP MORTALITY & 1 & 14 & 0.05 \\
STROKE & 0 & 3 & 0.21 \\
Return to theatre & 7 & 22 & 0.42 \\
AKI - FILTER & 6 & 26 & 0.16 \\
PPM & 3 & 7 & 0.96 \\
Respiratory Complication & 18 & 28 & 0.06 \\
GI complications & 2 & 5 & 0.50 \\
ITU stay (Median, IQR) & $3(2-6)$ & $3(2-7)$ & 0.25 \\
POST-OP HOSP STAY (MEDIAN, IQR) & $11(8-17)$ & $8(7-16)$ & 0.30 \\
\hline
\end{tabular}

\section{REFERENCES}

1. Cox JL. Intraoperative options for treating atrial fibrillation associated with mitral valve disease.J Thorac Cardiovasc Surg. 2001;122(2): 212-5.

2. Go AS, Hylek EM, Phillips KA, Chang Y, Henault LE, Selby JV et al. Prevalence of diagnosed atrial fibrillation in adults: national implications for rhythm management and stroke prevention: the AnTicoagulation and Risk Factors in Atrial Fibrillation (ATRIA) Study. JAMA. 2001.285(18): 2370-5.

3. Grigioni F, Avierinos JF, Ling LH, Scott CG, Bailey KR, Tajik AJ et al. Atrial fibrillation complicating the course of degenerative mitral regurgitation: determinants and long-term outcome. Am Coll Cardiol. 2002;40(1): 84-92.

4. Quader MA, McCarthy PM, Gillinov AM, Alster JM, Cosgrove DM 3rd, Lytle BW et al. Does preoperative atrial fibrillation reduce survival after coronary artery bypass grafting? Ann Thorac Surg . 2004; 77(5) :1514-22

5. Kannel WB, Abbott RD, Savage DD, McNamara PM. Epidemiologic features of chronic atrial fibrillation: the Framingham study. N Engl J Med. 1982; 306(17): 1018-22.

6. Dorian P, Jung W, Newman D, Paquette M, Wood K, Ayers GM et al. The impairment of health-related quality of life in patients with intermittent atrial fibrillation: implications for the assessment of investigational therapy. Am Coll Cardiol. 2000; 36(4): 1303-9

7. Saxena A, Dinh DT, Reid CM, Smith JA, Shardey GC, Newcomb AE. Does preoperative atrial fibrillation portend a poorer prognosis in patients undergoing isolated aortic valve replacement? A multicentre Australian study.Can J Cardiol. 2013; 29(6) :697-703.

8. Lin HJ, Wolf PA, Kelly-Hayes M, Beiser AS, Kase CS, Benjamin EJ, et al. Stroke severity in atrial fibrillation. The Framingham Study. Stroke. 1996;27(10):1760-4.

9. Thomas J Wang ${ }^{1}$, Martin G Larson, Daniel Levy, Ramachandran S Vasan, Eric P Leip, Philip A Wolf et al. Temporal relations of atrial fibrillation and congestive heart failure and their joint influence on mortality: the Framingham Heart Study. Circulation . 2003; 107(23): 2920-5.

10. Krahn AD, Manfreda J, Tate RB, Mathewson FA, Cuddy TE. The natural history of atrial fibrillation: incidence, risk factors, and prognosis in the Manitoba Follow-Up Study. Am J Med. 1995 May;98(5): 476-84.

11. Cox JL, Schuessler RB, D'Agostino HJ Jr, Stone CM, Chang BC, Cain ME, Coret al. The surgical treatment of atrial fibrillation. III. Development of a definitive surgical procedure. J Thorac Cardiovasc Surg. 1991;101(4): 569-83. 
12. Gaynor SL, Schuessler RB, Bailey MS, Ishii Y, Boineau JP, Gleva MJ, et al. Surgical treatment of atrial fibrillation: predictors of late recurrence.J Thorac Cardiovasc Surg. 2005; 129(1): 104-11.

13. Gammie JS, Haddad M, Milford-Beland S, Welke KF, Ferguson TB Jr, O'Brien SM et al. Atrial fibrillation correction surgery: lessons from the Society of Thoracic Surgeons National Cardiac Database. .Ann Thorac Surg. 2008;85(3): 909-14.

14. Pierri MD, Capestro F, Zingaro C, Torracca L. The changing face of cardiac surgery patients: an insight into a Mediterranean region.Eur J Cardiothorac Surg . 2010; 38(4): 407-13.

15. Calkins H, Brugada J, Packer DL, Cappato R, Chen SA, Crijns HJ et al.

HRS/EHRA/ECAS expert consensus statement on catheter and surgical ablation of atrial fibrillation: recommendations for personnel, policy, procedures and follow-up. A report of the Heart Rhythm Society (HRS) Task Force on Catheter and Surgical Ablation of Atrial Fibrillation developed in partnership with the European Heart Rhythm Association (EHRA) and the European Cardiac Arrhythmia Society (ECAS); in collaboration with the American College of Cardiology (ACC), American Heart Association (AHA), and the Society of Thoracic Surgeons (STS). Endorsed and approved by the governing bodies of the American College of Cardiology, the American Heart Association, the European Cardiac Arrhythmia Society, the European Heart Rhythm Association, the Society of Thoracic Surgeons, and the Heart Rhythm Society. Europace. 2007; 9(6): 335-79.

16. Damiano RJ Jr, Gaynor SL, Bailey M, Prasad S, Cox JL, Boineau JP et al. The long-term outcome of patients with coronary disease and atrial fibrillation undergoing the Cox maze procedure. $J$ Thorac Cardiovasc Surg.2003;126(6):2016-21.

17. MacGregor RM, Khiabani AJ, Bakir NH, Manghelli JL, Sinn LA, Carter DI, et al. Impact of age on atrial fibrillation recurrence following surgical ablation. Thorac Cardiovasc Surg. 2020: S0022-5223(20) 30745-5.

18. Ad N, Henry L, Hunt S, Holmes SD, Halpin L. Results of the Cox-Maze III/IV procedure in patients over 75 years old who present for cardiac surgery with a history of atrial fibrillation. J Cardiovasc Surg (Torino). 2013; 54(2) :281-8.

19. Bunch TJ, May HT, Bair TL, Anderson JL, Crandall BG, Cutler MJ et al. Long-Term Natural History of Adult Wolff-Parkinson-White Syndrome Patients Treated With and Without Catheter Ablation. Circ Arrhythm Electrophysiol.2015; 8(6): 1465-71.

20. Gillinov AM, Saltman AE. Ablation of atrial fibrillation with concomitant cardiac surgery. Semin Thorac Cardiovasc Surg. 2007; 19(1): 25-32.

21. Ad N, Barnett SD, Haan CK, O'Brien SM, Milford-Beland S, Speir AM. Does preoperative atrial fibrillation increase the risk for mortality and morbidity after coronary artery bypass grafting? $J$ Thorac Cardiovasc Surg. 2009;137(4) :901-6

22. Wang B, Xu ZY, Han L, Zhang GX, Lu FL, Song ZG. Impact of pre-operative atrial fibrillation on mortality and cardiovascular outcomes of mechanical mitral valve replacement for rheumatic mitral valve disease. Eur J Cardiothorac Surg.2013; 43(3) :513-9.

23. Ngaage DL, Schaff HV, Mullany CJ, Barnes S, Dearani JA, Daly RC, et al.Top of ForBottom of Form Influence of preoperative atrial fibrillation on late results of mitral repair: is concomitant ablation justified? Ann Thorac Surg. 2007;84(2): 434-42.

24. Ngaage DL, Schaff HV, Mullany CJ, Sundt TM 3rd, Dearani JA, Barnes S et al. J. Does preoperative atrial fibrillation influence early and late outcomes of coronary artery bypass grafting? Thorac Cardiovasc Surg. 2007;133(1): 182-9. 
25. Ngaage DL, Schaff HV, Barnes SA, Sundt TM 3rd, Mullany CJ, Dearani JA et al. Prognostic implications of preoperative atrial fibrillation in patients undergoing aortic valve replacement: is there an argument for concomitant arrhythmia surgery? Ann Thorac Surg. 2006;82(4): 1392-9.

26. Calkins H, Hindricks G, Cappato R, Kim YH, Saad EB, Aguinaga L et al. 2017 HRS/EHRA/ECAS/APHRS/SOLAECE expert consensus statement on catheter and surgical ablation of atrial fibrillation. Europace. 2018;20(1) :e1-e160

27. Ad N, Holmes SD, Pritchard G, Shuman DJ. Association of operative risk with the outcome of concomitant Cox Maze procedure: a comparison of results across risk groups. J Thorac Cardiovasc Surg. 2014; 148(6) :3027-33.

28. Ad N, Henry L, Holmes SD, Stone LE, Hunt S. The association between early atrial arrhythmia and long-term return to sinus rhythm for patients following the Cox maze procedure for atrial fibrillation. Eur $J$ Cardiothorac Surg. 2013; 44(2) :295-300

29. Gu W, Guo H, Lu C, Huang H, Liu J, Liu J et al. Surgical ablation for persistent atrial fibrillation in concomitant cardiac surgery: mid-long-term result. Eur J Cardiothorac Surg. 2017;52(5): 888-894.

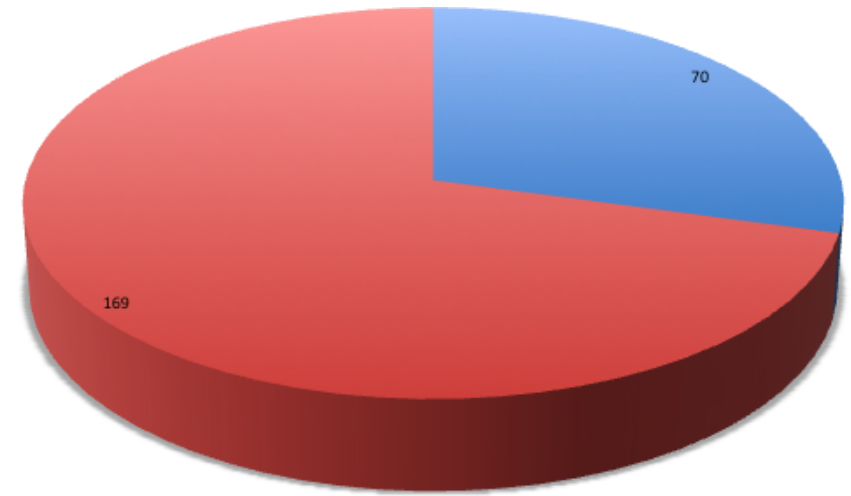

$=$ Cox-Maze

- No Surgical Af treatment

Freedom from AF between Maze and Nil procedure

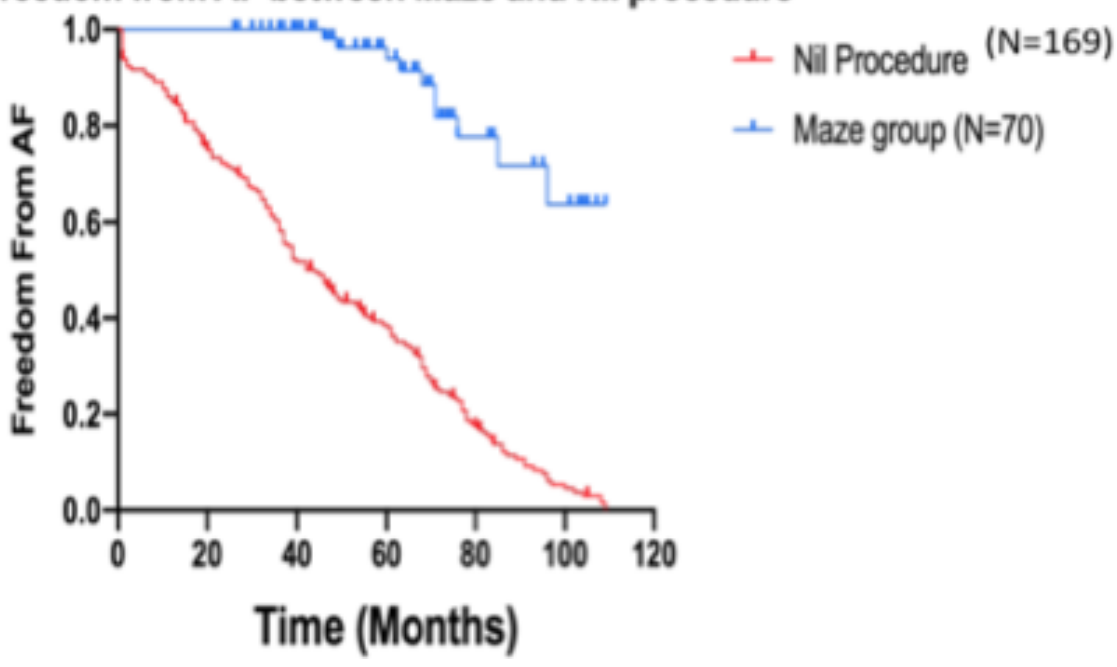


Survival Between Maze group and no procedure

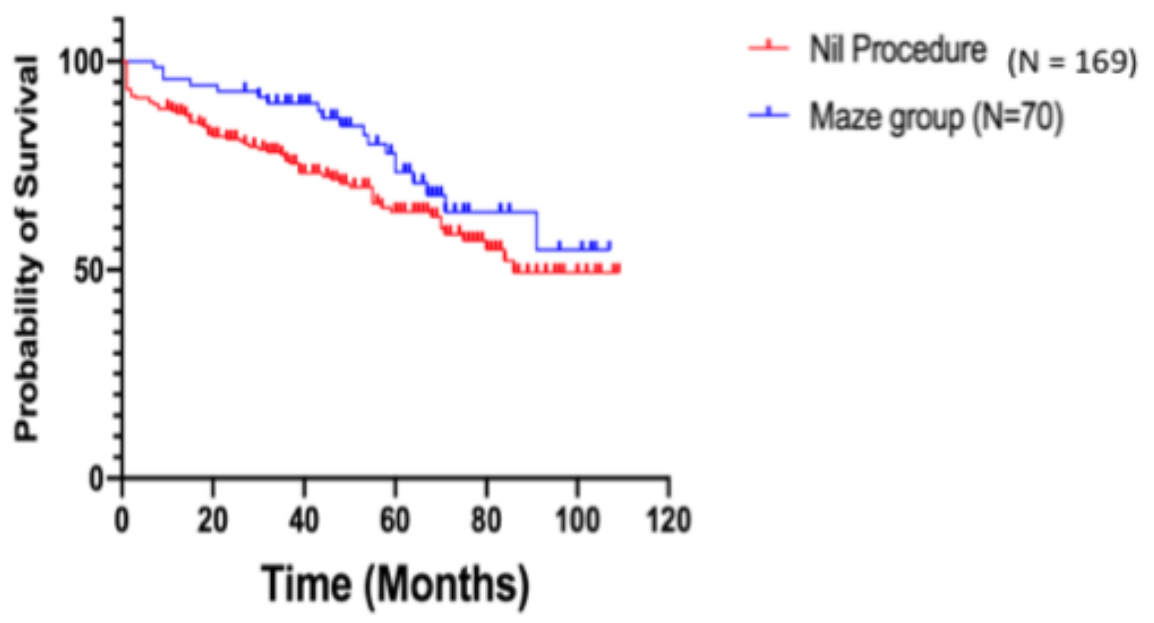

NYHA 1 status between Maze and Nil procedure

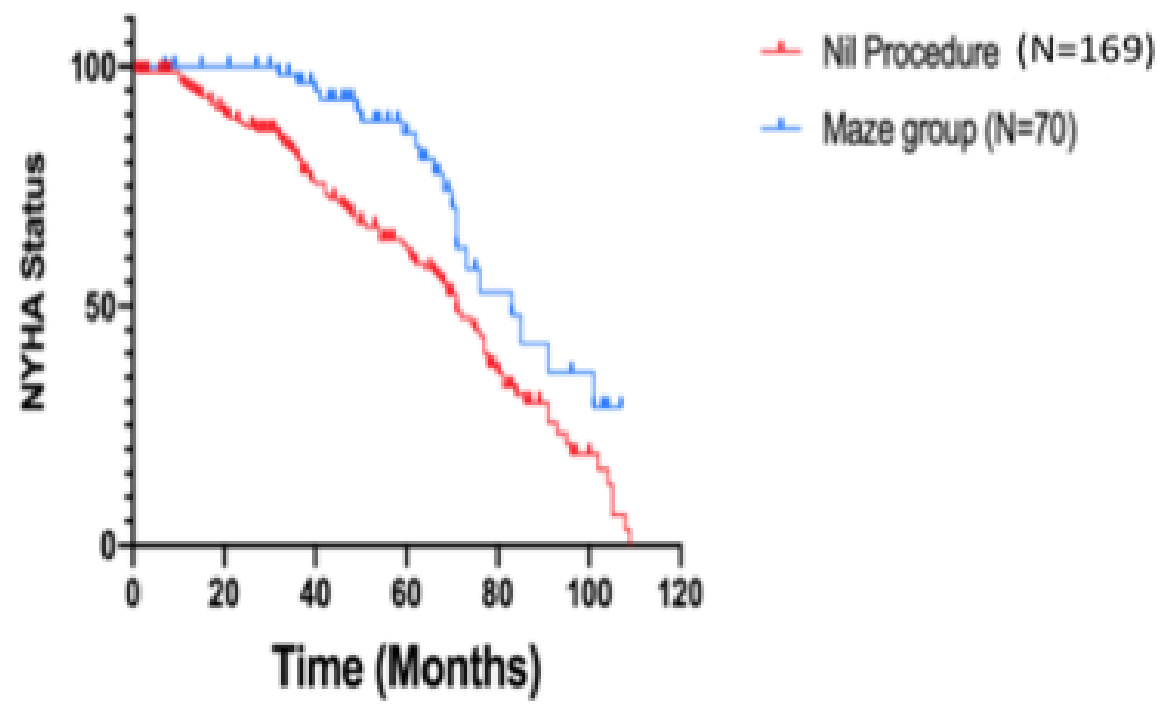

